\title{
Congenital Lung Lesions (CL): Postnatal Management: Operative Intervention or Serial Observation: A Review of 2 Cases
}

\author{
Niraj Kumar Dipak*, Deepa shetty, Sudha Rao, Praful Ramdas Shanbhag, Avinash \\ Desai, Manjula Rupani.
}

Department of Neonatology, B J Wadia Hospital for Children, Nowrosjee Wadia Maternity Hospital, Acharya Donde M arg, Parel, M umbai 400012, M aharashtra, India.

\section{ABSTRACT}

\begin{abstract}
Background: Antenatal diagnosis of CLLs can be made as early as 18 weeks of gestation and sequential scanning guides in fetal intervention, or in adopting conservative management. Pregnancy outcome depends upon many factors such as mediastinal shift, presence of pleural effusion, ascites, hydrops, chromosomal anomalies and malformations involving other systems.

Case characteristics: We present a series of 2 cases presented prenatally as CLL and managed differently, one with operative intervention whereas other one with serial observation

Conclusion: The best postnatal management is uncertain for these lesions and informed consent for operative intervention must include current state of evidence.

KEY WORDS: Cystic Adenomatoid M alformation, Bronchpulmonary Sequestration, Tho racotomy, Conservative M anagement, Echolucent, Polyhydramnios.
\end{abstract}

Address for correspondence: Dr. Niraj Kumar Dipak, Department of Neonatology, BJ Wadia hospital for children, Nowrosjee Wadia maternity hospital, Acharya Donde M arg, Parel, M umbai 400012, M aharashtra, India. M obile no.: +919819020036E-Mail: neonatalfundas@ gmail.com

\begin{tabular}{|c|c|}
\hline \multicolumn{2}{|r|}{ Online Access and Article Informtaion } \\
\hline Quick Response code & International Journal of Integrative Medical Sciences \\
\hline \multirow{2}{*}{ 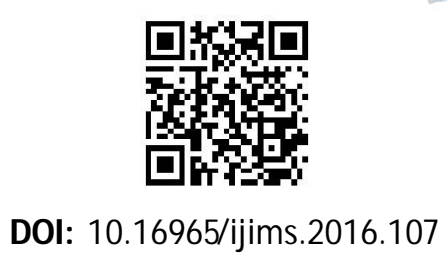 } & www.imedsciences.com \\
\hline & $\begin{array}{ll}\text { Received: 15-02-2016 } & \text { Accepted: 23-02-2016 } \\
\text { Reviewed: 16-02-2016 } & \text { Published: 29-02-2016 }\end{array}$ \\
\hline Source of Funding: Self & Conflicts of interest: None \\
\hline
\end{tabular}

\section{INTRODUCTION}

Great developments have been made in the understanding of congenital lung lesions (CLL) over the last 2 decades, especially when diagnosed prenatally [1]. Now most of the investigators agree that that majority of pregnancies with an affected fetus can be carried with an excellent outcome. Outcome depends upon size, volume, location, presence of a systemic arterial supply, mediastinal shift and presence of pleural effusion, ascites, hydrops, chromosomal anomalies and malformations involving other systems [2]. Postnatal management of children with symptomatic congenital lung malformations is reasonably straight forward but the need for intervention in asympt- omatic lesion and timing of surgical intervention in infants with symptomatic lesions is an highly debatable issue. We are reporting series of 2 cases who presented antenatally as CLL and managed differently in the postnatal period. Another issue of contention is best surgical option: thoracotomy versus thoracoscopy and how much to resect: segmental resection versus lobectomy.

\section{CASE REPORT}

Case 1: A 26 year old mother in her 28 weeks of pregnancy was referred to us for antenatal detection of mixed echogenic mass with no vascularity, suggestive of cystic adenomatoid malformation(CCAM) in the left thorax. Serial 
scan depicted polyhydramnios in 33.2 and 36.5 weeks scan. Fetal ascites was noted at 31 weeks [Table 1]. She went into spontaneous labor at 37 weeks of gestation. A $2.9 \mathrm{~kg}$ male baby, length being $51 \mathrm{~cm}$ and head circumference 34.5 $\mathrm{cm}$, (all between $50-97 \%$ ) was delivered vaginally and required positive pressure ventilation at birth. He was initiated on mechanical ventilation (MV) for severe respiratory distress. Postnatal USG was suggestive of CCAM. CT scan with pulmonary angiogram revealed pulmonary trunk measuring $9 \mathrm{~mm}$ with the main right and left pulmonary arteries being normal in origin, course and caliber. There was large multicystic lesions involving almost whole of left lung field causing compression and shifting of mediastinum towards right side, volume of right lung field was reduced, largest of cyst size being approx $10 \mathrm{x}$ $9 \mathrm{~mm}$. There was no evidence of any abnormal vascular abnormalities favouring possibility of CCAM type 2 [Figure 1]. Considering the persistence of ventilator requirement and constant mediastinal shifting, he was operated on day 5 of birth by open thoracotomy and left lower lobe sparing lobectomy. Post operatively baby did well, extubated after 3 days of respiratory support and he was discharged home on day 10 with out- patient follow up [Table 2]. Currently he is 5 months old, has fairly good growth parameters, no ongoing medical issues and no history of emergency room visit with complaints of rapid breathing.

Fig. 1: CT Thorax depicting lesions of left Lung.

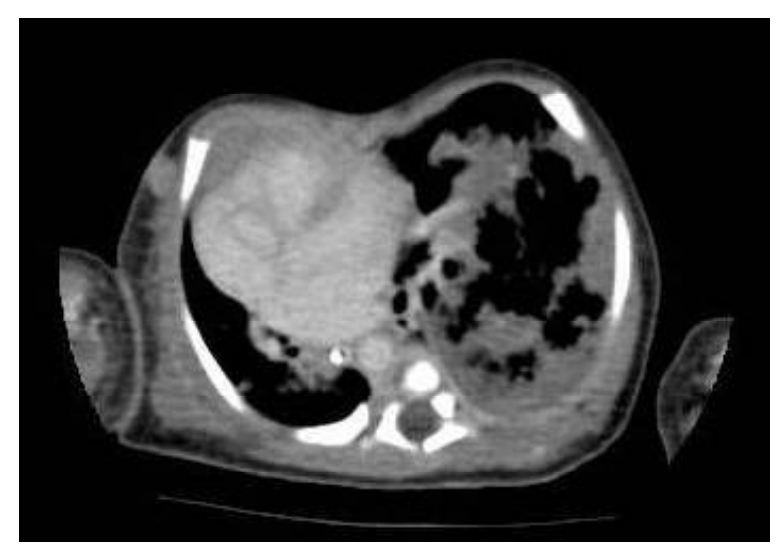

Case 2: A 29 year old third gravidae mother was referred to us at 29 weeks for antenatal detection of thoracic homogenous echogenic mass with vascularity suggestive of sequestration [Table 1]. Serial scan showed persistence of the lesion. Pregnancy was complicated by polyhydramnios which was detected in all scans since mother was referred to us but no hydrops or ascited was noted. Elective lower segment caesarean section (LSCS) was done for persistence of polyhydramnios at 35.5 weeks. A male baby of $2.51 \mathrm{~kg}$, length being $48 \mathrm{~cm}$ and head circumference $33 \mathrm{~cm}$ (all between 50-75\%), developed respiratory distress soon after birth. He was initiated on MV for severe respiratory distress. Postnatal ultrasonography (USG) showed a large echogenic segment on left lower zone of the lung not communicating with rest of left lung with no evidence of any air echo and a $2.2 \mathrm{~mm}$ vessel was seen supplying it. CT chest and angio showed a large non aerated lung tissue seen in the left lower lobe region with no communication with tracheobronchial tree. A large $2.5 \mathrm{~mm}$ accessory systemic artery was seen supplying it arising from the lateral wall of the lower descending thoracic aorta [figure 2]. CT report concluded extralobar sequestration (ELS) in left lower lobe of the lung. He was gradually weaned off from the ventilator and extubated on day 9 of life, further was continued on noninvasive positive pressure ventilation over next 7 days and stayed on low flow oxygen by nasal prongs till day 28 of life. He was discharged on day 29 of life once he started maintaining Spo 2 94-96\% off 02 and on direct breast feeds with

Fig. 2: showing the feeding vessels of the ELS rising from the lateral wall of the lower descending thoracic aorta.

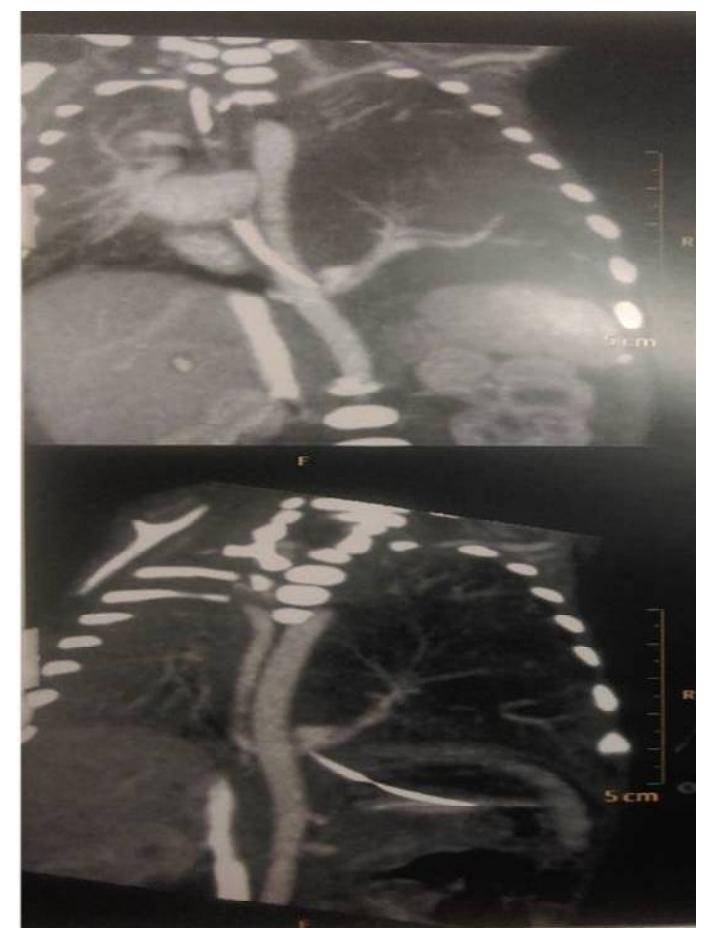




\begin{tabular}{|c|c|c|c|c|c|c|}
\hline Case & $\begin{array}{c}\text { Fetal scan } \\
\text { abnormality }\end{array}$ & $\begin{array}{c}\text { Serial fetal scans } \\
\text { (gestation in weeks) }\end{array}$ & Polyhydramnios & $\begin{array}{c}\text { Hydrops/ ascites/ } \\
\text { pleural effusion }\end{array}$ & Pregnancy & $\begin{array}{c}\text { Lesions } \\
\text { persistence } \\
\text { during } \\
\text { pregnancy }\end{array}$ \\
\hline $\mathbf{1}$ & $\begin{array}{c}\text { Mixed echogenic } \\
\text { mass,no } \\
\text { vascularity(ccam) }\end{array}$ & $28-31-33.2-36.5$ & $\begin{array}{c}\text { Present at 33.2 and } \\
36.5 \text { weeks scan }\end{array}$ & $\begin{array}{c}\text { Fetal ascites noted at } \\
31 \text { weeks but not at } \\
33.2 \text { and 36.5 weeks }\end{array}$ & Singleton & Persistent \\
\hline $\mathbf{2}$ & $\begin{array}{c}\text { Homogenous } \\
\text { echogenic mass with } \\
\text { vascularity } \\
\text { (sequestration) }\end{array}$ & $29.4-32-35.4$ & Present in all scans & Nil & Singleton & Persistent \\
\hline
\end{tabular}

Table 1: Pregnancies with CLL and their outcome.

Table 2: Postnatal management: operative intervention or serial observation.

\begin{tabular}{|c|c|c|c|c|c|c|c|c|}
\hline Case/Sex & $\begin{array}{l}\text { Gestational } \\
\text { age/ birth } \\
\text { weight }\end{array}$ & Presentation & $\begin{array}{l}\text { USG with } \\
\text { doppler }\end{array}$ & CT scan & Histology & $\begin{array}{c}\text { Operative } \\
\text { intervention }\end{array}$ & $\begin{array}{c}\text { Associated } \\
\text { anomaly }\end{array}$ & Outcome \\
\hline $1 /$ Male & $\begin{array}{c}37 \text { weeks/ } \\
2.9 \mathrm{~kg}\end{array}$ & Symptomatic & CCAM & $\begin{array}{l}\text { CCAM type } 2 \text { (There are three } \\
\text { to four large cystic lesions } \\
\text { which are surrounded by } \\
\text { small cystic lesions.No } \\
\text { evidence of any abnormal } \\
\text { vascular abnormalities) }\end{array}$ & $\begin{array}{c}\text { Surgical } \\
\text { intervention/CCAM } \\
\text { type } 2 \text { (scattered cysts } \\
\text { lined by olumnar } \\
\text { epithelium) }\end{array}$ & $\begin{array}{l}\text { Open thoracotomy } \\
\text { and lower lobe } \\
\text { sparing lobectomy }\end{array}$ & Nil & $\begin{array}{c}\text { Adquate gro } \\
\text { wth / Nil } \\
\text { emergency } \\
\text { room visit } \\
\text { with } \\
\text { complaints } \\
\text { of rapid } \\
\text { breathing }\end{array}$ \\
\hline 2/Male & $\begin{array}{c}35.5 \text { weeks/ } 2.51 \\
\mathrm{~kg}\end{array}$ & Symptomatic & & $\begin{array}{l}\text { ELS with vessel arising from } \\
\text { descending aorta,venous } \\
\text { drainage via an accessory vein } \\
\text { to azygous vein }\end{array}$ & $\begin{array}{l}\text { conservative } \\
\text { strategy/observation }\end{array}$ & Nil & Nil & $\begin{array}{c}\text { Adequate } \\
\text { growth /1 } \\
\text { emergency } \\
\text { room visit } \\
\text { and short } \\
\text { admission } \\
\text { for lower } \\
\text { respiratory } \\
\text { tract } \\
\text { svmntoms }\end{array}$ \\
\hline
\end{tabular}

CCAM - Congenital Cystic Adenomatoid Malformation, ELS - Extralober Sequestration, USG - Ultrasonography, CT scan-Computed Tomography Scan

outdoor follow up. At the time of writing he is 6.5 months of age, of adequate growth and development, with history of one emergency room visit and subsequent short admission of 3 days for lower respiratory tract infections apart from few outpatient visits for minor ailments and immunization [Table 2].

\section{DISCUSSION}

CLLs may create a mass effect within the fetal thorax and it may compress the surrounding lung resulting in lung hypoplasia, can cause mediastinal shift and compression of fetal heart and great vessels leading to hydrops. Additionally polyhydramnios may result if mediastinal compression interferes with swallowing [3].

Antenatal appearance of thoracic masses can be hyperechoic or echolucent. Echolucent cysts are Type 1 and Type 2 CCAM, congenital diaphragmatic hernia (CDH), bronchogenic cysts, whereas homogenous hyperechoic lung mass include CCAM Type 3, bronchopulmonary sequestration (BPS), mediastinal teratoma and neuroblastoma.[4] Doppler studies demonstrate systemic vascular supply in BPS. Peristalsis of the bowel within the chest, and absence of normal stomach bubble differentiate $\mathrm{CDH}$ from Type 1 CCAM . Once a Thoracic mass is detected, careful search for associated anomalies including fetal ECHO should be considered, Doppler studies should be performed to look for feeding vessel, presence of hydrops and mediastinal shift should be noted.

CCAM is a pulmonary lesion that is characterized by an overgrowth of terminal bronchioles forming cysts of various sizes. The lesion communicates with the bronchial tree and derives its vascular supply from pulmonary circulation. The lesion is usually unilateral and only one lobe is affected in $80-95 \%$ of the cases. Stocker initially classified it into 3 types [5] and later expanded it to 5 types [6] and changed the nomenclature to congenital pulmonary airway malformation (CPAM). Type 1 lesions account for $50 \%$ of postnatal cases and characterized by large cysts (up to $7 \mathrm{~cm}$ ) lined with ciliated pseudostratified epithelium, associated with a 
good outcome. Type 2 lesions account for 40\% of the postnatal cases, lined with tall columnar epithelium associated with other anomalies and have a somewhat poorer prognosis. Type 3 lesions have a share of just $10 \%$ and have worst prognosis consisting of homogenous microcystic mass lined with cuboidal epithelium.

BPS are regions of nonfunctional lung parenchyma lacking a normal connection to the tracheobronchial tree. The characteristic of BPS is the anomalous blood supply usually arising from aorta or its major branches. Lesions are almost always unilateral, left side is more affected and located in the lower lobe. ELS have a separate pleura and more diagnosed in fetus and neonate, like in the case 2 whereas intralobar sequestration (ILS) share the same pleura as the surrounding lung and more common in infants and children.

Antenatally diagnosed BPS often spontaneously involutes to become nearly undetectable at birth [7]. It is essential that an accurate identification of the vascular supply be made in all cases of BPS and hybrid BPS/CCAM. The presence of hydrops is single most important prognostic factor in the assessment. The prognosis is better in isolated ascites and pleural effusion $[8,13]$, like in our cases.

All fetuses with CLL should be delivered at a tertiary care centre that is capable of managing pulmonary hypoplasia. Therapeutic needs may vary, with some infants require no respiratory support, and others requiring high frequency oscillatory ventilation and extracorporeal membrane oxygenation (ECM O). Large pleural effusions should be drained immediately by tube thoracotomy. The sequence of radiological investigations during the postnatal should be ultrasound, Doppler, followed by CT or MRI scanning.

Proponents of early surgical intervention argue for the possible discordance between presumptive radiological diagnosis and final pathological diagnosis, risk of recurrent infections, pneumothoraxand delayed malignant transformation, particularly in CCAM [9] whereas those who support serial observation question the safety of pulmonary resection in infancy and childhood.

Int J Intg M ed Sci 2016;3(2):232-36. ISSN 2394 - 4137
Complete surgical resection of affected lobe in symptomatic CCAM lesions is recommended. Surgical resection in BPS may be complicated by the presence of an anomalous blood supply. Recent studies suggest that these infants particularly with ELS may be managed conservatively without surgical intervention as we adopted in case 2 . While recurrent infection is a common complication of ILS, this is not the case with ELS. However, drawback of this approach is the diagnosis of ELS, is not $100 \%$ certain based on imaging, and there is a high rate of synchronous malformations such as CCAM (with a risk of malignant transformation). Chetcutiand Crabbe reported that they followed up more than 100 children with antenatally diagnosed CLL. From this group, approximately $10 \%$ showed neonatal symptoms and underwent surgery, approximately 5\% developed lower respiratory tract infections, and the remaining are under follow-up and remain symptom-free [10].

The timing of surgery in symptomatic infants also remains controversial. Many would delay the surgery until after 2-3 months of age to decrease anaesthetic risks and the need for postoperative ventilator support [11]. Some recommend early intervention to take advantage of compensatory lung growth in early months of life [12]. The long term outcome of the LoTOS study [13] may provide answers to this ongoing debate of surgical intervention, its timing versus conservative/observation strategies.

Another contentious issue is best surgical option. Open thoracotomy has been the tradional standard for resection of CLLs. But thoracoscopy has been increasingly used for CLL. Neonatal thoracoscopic lobectomy is associated with minimal morbidity $[14,15]$. Lobectomy is preferred in CLLS whereas segmental resections should be reserved for very localized malformations like small ILSand for rare patients with multilobar or bilateral involvement. In BPS a new alternative to surgery is coil embolization. This minimally invasive procedure has been safely performed for pulmonary sequestration and has also been shown to result in complete or near-complete regression of the lesion within a few months of the procedure [16,17], but long term follow up studies are not yet available. 


\section{CONCLUSION}

Outcome of fetuses with CLLs depends upon presence of hydrops, polyhydramnios and mediastinal shifting.[18] The best postnatal management is uncertain for these lesions as conservative management or need for, and timing of, surgical intervention is debated.[19] Based on the current uncertainty, informed consent for the operative intervention must include detailed discussions and the current state of evidence [1].

\section{ACKNOWLEDGEMENT}

Authors thank to MD, Dr. Amdekar and MS, Dr. aswini, BJ Wadia Hospital for Children, Mumbai for permitting them to publish the manuscript.

\section{REFERENCES}

[1]. Puligandla P S, Laberge J M : Clin Perinatol 2012;39:331-347.

[2]. Bromley B, Parad R, Estroff J A: Fetal lung masses: prenatal course and outcome. J Ultrasound Med 1995;14:927-36.

[3]. Adzick NS, Harrison M R, Crombleholme TM : Fetal lung lesions: management and outcome. Am j obstet gynecol 1998;179:884-889.

[4]. Achiron R, Strauss S, Seidman DS: Fetal lung hyperechogenicity: Prenatal ultrasonographic diagnosis, natural history and neonatal outcome. Ultrasound Obstet Gynecol 1995;6:40-42.

[5]. Stocker JT, M adewell JE, Drake RM : Congenital cystic adenomatoid malformation of the lung. Classification and morphologic spectrum. Hum Pathol 1977;8:155-71.

[6]. Stocker JT: Congenital pulmonary airway malformation: a new name and an expanded classification of congenital cystic adenomatoid malformations of the lung. Histopathology 2002;41:424-31.

[7]. Morin L, Crombleholme TM, D'Alton ME: Prenatal diagnosis and management of fetal thoracic lesions. Semin Perin 1994;18:228-53.
[8]. Thorpe-Beeston JG, Nicolaides KH: Cystic adenomatoid malformation of the lung: prenatal diagnosis and outcome. Prenat Diagn 1994;14:67788.

[9]. d'Agostino, Bonoldi E, Dante S: Embryonal rhabdomyosarcoma of the lung arising in cystic adenomaoid malformation: Case report and review of literature. J Pediatr Surg 1997;32:1381-1383.

[10]. Chetcuti PA, Crebbe DC: CAM lungs: the conservative approach. Arch Dis Child Fetal Neonatal Ed 2006;91:F 463-4.

[11].Calvert JK, Lakhoo K: Antenatally suspected congenital cystic adenomatoid malformation of the lung: postnatal investigation and timing of surgery. J pediatr Surg 2007;42:411-4.

[12]. Frenckner B, Freyschuss U: Pulmonary function after lobectomy for congenital lobar emphysema and cystic adenoidmatoid malformation. A follow-up study. Scand J Thoracic Cardiovasc Surg 1982;16:293-8.

[13]. Jaffe A, Chitty LS: Congenital cystic adenomatoid malformations may not require surgical intervention. Arch Dis Child Fetal Neonatal Ed 2006;91:F464.

[14]. Kaneko K, Ono Y, Tainaka T: Thoracoscopic lobectomy for congenital cystic lung disease in neonates and small infants. Pediatr surg int 2010;26:361-5.

[15]. Rothenberg SS, Kunzler KA, Middlesworth W: Thoracoscopic lobectomy in infants less than 10 $\mathrm{kg}$ with prenatally diagnosed cystic lung disease. J Laparoendosc Adv Surg Tech A 2011;21:181-4.

[16]. Tokel K, Boyvat F, Varan B: Coil embolization of pulmonary sequestration in two infants: a safe alternative to surgery. AJ R 2000;175:993e5.

[17]. Yeh CN, Wang JN, Tsai YC, Yao CT, Lin CS, Wu JM : Coil embolization of pulmonary sequestration in two infants a safe alternative management. Acta Pediatr Taiwan 2006;47:88e91.

[18]. Davenport M, Warne SA, Cacciaguerra S: Current outcome of antenatally diagnosed cystic lung disease. J Pediatr Surg 2004;39:549-56.

[19]. Hammond PJ, Devdas JM, Ray B: The outcome of expectant management of congenital cystic adenomatoid malformations (CCAM) of the lung. Eur J Pediatr Surg 2010;20:145-9.

\section{How to cite this article:}

Niraj Kumar Dipak, Deepa shetty, Sudha Rao, Praful Ramdas Shanbhag, Avinash Desai, M anjula Rupani. Congenital Lung Lesions (CLL): Postnatal M anagement: Operative Intervention or Serial Observation: A Review of 2 Cases. Int J Intg M ed Sci 2016;3(2):232-236. DOI: 10.16965/ijims.2016.107 